\title{
Influence of coordination abilities on speed endurance of schoolchildren with different typologies
}

Georgiy Polevoy ${ }^{1}$

Sri Lanka Journal of Child Health, 2019; 48(3): 246-250

\begin{abstract}
Introduction: Differentiated development of coordination abilities in children with different strengths of the nervous system has a positive impact on the development of speed endurance. However, there are no such studies.
\end{abstract}

Objective: To determine the effect of coordination training on development of coordination abilities and speed endurance abilities of children 7-8 years with different strengths of the nervous system.

Method: Pedagogical research was carried out for 7 months at school with children 7-8 years, a total of 60 children taking part. All the children were admitted to physical education classes for health reasons and divided into three groups of 20 each using the method of random sampling. The study used tests that determine the level of development of coordination abilities (shuttle run), speed endurance (jump over the rope) and strengthweakness of the nervous system in the process of excitation (tapping test). The programs Bio-Stat, Excel and parametric criterion T-Student were used in statistical and mathematical processing of the results.

Results: After the study, new results were obtained. In children from the first group (KG) coordination abilities became worse by 0.1 seconds; at the same time, speed endurance abilities improved from $28.4 \pm 2.1$ to $29.3 \pm 1.8(\mathrm{p}>0,05)$. Children in the second group (EG-1) improved their performance in the test "shuttle run" from $10.3 \pm 0.6$ to $10.1 \pm 0.5$ ( $p>0.05)$, and in the test "jump over the rope" the

\footnotetext{
${ }_{1}^{1}$ Associate Professor, Department of Physical Education, VyatGGU and Coach, VyatGGU National Football Team, Vyatka State University Kirov, Russian Federation

*Correspondence: gera_lider1@mail.ru

(iD)

orcid.org/ 0000-0002-3300-3908
}

(Received on 29 October 2018: Accepted after revision on 21 December 2018)

The authors declare that there are no conflicts of interest

Personal funding was used for the project.

Open Access Article published under the Creative

Commons Attribution CC-BY (cC) (†) License results improved from $31.1 \pm 1.7$ to $36.2 \pm 2.1$ $(\mathrm{p}<0.05)$. Children in the third group $(\mathrm{EG}-2)$ had significantly improved their performance in both control exercises. In the test "shuttle run", performance improved from $10.3 \pm 0.6$ to $9.7 \pm 0.5$ $(p<0.05)$, and speed endurance improved by 9.2 $(\mathrm{p}<0.05)$.

Conclusions: The study showed the effectiveness of the typological criterion in differentiating children into groups. If the physical education classes at school to develop coordination abilities of schoolchildren taking into account the strength of the nervous system, it will significantly improve the performance of coordination abilities and speed endurance.

DOI: http://dx.doi.org/10.4038/sljch.v48i3.8760

(Keywords: differentiated approach, coordination abilities, schoolchildren, nervous system strength, speed endurance)

\section{Introduction}

Physical abilities of a person are today classified as strength, speed, endurance, flexibility and coordination abilities. The importance of coordination abilities in human activities cannot be over-emphasized. A high level of coordination of movement allows a person to quickly and accurately perform motor action, economically expending their strength ${ }^{1-3}$. A favourable period for the development of coordination abilities is primary school age ${ }^{4,5}$. The influence of coordination abilities on other physical qualities has been studied $^{6,7}$. The studies showed a high level of correlation between the coordination of movement and speed endurance. Speed endurance is the ability to maintain high speed for as long as possible ${ }^{1}$.

In work with children, especially primary school age children, a differentiated approach is often used. This approach helps to reveal the internal and external potential of children, the hidden reserves of the body ${ }^{8,9}$. The differentiated approach is used not only in sports work, but also at school; thus, children can be differentiated on performance of physical exercises into different groups taking into account age, sex, level of technical or physical preparation, growth, weight and many other 
indicators ${ }^{10,11}$. One of the effective criteria for differentiation of children into groups is the typological criterion. Typology is a feature of the manifestation of the properties of the nervous system. Along with lability and mobility of the nervous system there is its strength. Most researchers devote a significant impact strengthweakness of nervous system for the excitation process $^{12,13}$.

Thus, despite the study of this issue on the problem of coordination abilities, their interaction with other physical qualities and the effectiveness of the use of typology as a criterion of differentiation of children into groups in the performance of physical exercises, it was not possible to find studies that show the impact of coordination training on the development of speed endurance of children 7-8 years with different strength of the nervous system. The hypothesis of the study is that coordination abilities and speed endurance will improve, if physical education classes are conducted for 12-15 minutes at school, taking into account the strength and weakness of the nervous system of children.

\section{Objectives}

To determine the effect of coordination training on development of coordination abilities and speed endurance abilities of children 7-8 years with different strengths of the nervous system.

\section{Method}

The study was conducted in Russia, in the city of Kirov, secondary school 10. All procedures performed in studies involving human participants were in accordance with the ethical standards of the institutional and/or national research committee and with the 1964 Helsinki declaration and its later amendments or comparable ethical standards. Informed consent was obtained from all individual participants included in the study.

Sixty schoolchildren aged 7-8 years from the first class took part in pedagogical research. All children were healthy and allowed physical training. Prior to the study, all 60 schoolchildren were differentiated into three identical groups based on coordination abilities ${ }^{14}$. The first group is a control group (KG) which included children who were engaged in the standard method of physical education for schoolchildren from the first class ${ }^{15}$. The second group is an experimental group-1 (EG-1) which included children who were engaged in the standard method, ${ }^{15}$ but, at the same time, after a warm-up, they performed physical exercises to develop coordination abilities for 12-15 minutes. The exercises were simple and accessible to perform - jumping, somersaults, running, exercises with a Hoop, a stick, a ball and many others. The difficulty in performing coordination exercises increased due to the introduction of new elements, increasing the speed of the exercise, changing the trajectory of movement and some other method ${ }^{1}$. The third group is an experimental group-2 (EG-2) which included children who were engaged in the standard method ${ }^{15}$ and performed coordination exercises for 12-15 minutes. Training in EG-2 differed from training in EG-1 in that in EG-2 coordination exercises were given, taking into account the strength of the nervous system of schoolchildren. In this case, the criterion of differentiation of children into groups was a typological criterion, namely, strength-weakness of the nervous system in the process of excitation. When performing physical exercises for schoolchildren with a strong nervous system, an intensive load was used (increased by reducing the rest time and increasing the number of exercises), and for schoolchildren with a weak nervous system, the load was volumetric (increased by increasing the number of repetitions of the exercise and increasing the rest time $)^{13,16,17}$. The intensity of performing exercise (140-160 beats per minute), rest time (up to full recovery, pulse 100-120 beats per minute) the nature of recreation (passive) were the same for players with strong and weak nervous system. The duration of performing exercise for the players with a strong nervous system was 1-2 minutes and for the players with a weak nervous system was 2-3 minutes. The number of repetitions for players with a strong nervous system was 5-7 times in the series, and for the players with a weak nervous system was 6-8 times. The number of series for the players with a strong nervous system was 5-7 and for the players with a weak nervous system weak 6-8.

During the study period, 59 physical education classes were held in each group for 30 weeks. All classes were held twice a week for 45 minutes. Before and after the study, all schoolchildren passed tests on the level of development of coordination abilities (shuttle run), speed endurance (jump over the rope), and schoolchildren from EG2 were differentiated into two subgroups, taking into account the strength-weakness of the nervous system (tapping test).

\section{Shuttle run $3 \times 10^{15}$}

Two lines are marked at a distance of 10 metres from each other. At the command of the coach, schoolchildren must run from the first line to the second and touch it with their hand, then go back and touch the first line with their hand and then finish crossing the second line.

Jump over the rope $e^{15}$

Starting position for jumps: stand upright, throw 
the rope behind his back, gaze direct in front of you, slightly bend your arms at the elbows, hands to take on $15-20 \mathrm{~cm}$ from the thighs. While in the starting position, start to rotate the rope. The total number of jumps within one minute is calculated.

Tapping test ${ }^{18}$

A sheet of paper (A-4) shows 6 squares. At the command of the coach, all children begin to put points at the maximum pace in the first square for five seconds. Then they go to the second square, the third and so on. The exercise ends after the sixth square. After the exercise, the total number of points is calculated and a graph is plotted. The graph determines the strength of the nervous system.
Mathematical and statistical processing of results was carried out using the program Bio-Stat 2009 Excel. The parametric criterion T-Student was used, the result was considered significant at $\mathrm{p}<0.05$. $^{19}$

\section{Results}

Prior to the study, all children were tested for the level of development of coordination abilities and were differentiated into three equal groups $(\mathrm{p}>0.05)$. Children from EG-2 were differentiated into 2 subgroups according to the strength of the nervous system. New results were obtained after the study (Table 1).

Table 1

Change in indicators of coordination abilities and speed endurance of children with different nervous system

\begin{tabular}{|c|c|c|c|c|}
\hline \multicolumn{5}{|c}{$(\boldsymbol{M} \pm \boldsymbol{m})$} \\
\hline Indicators & Group & Before & After & $\mathrm{p}$ \\
\hline \multirow{2}{*}{$\begin{array}{c}\text { shuttle run } \\
\text { (seconds) }\end{array}$} & KG & $10,3 \pm 0,6$ & $10,4 \pm 0,6$ & $>0,05$ \\
\cline { 2 - 5 } & EG-1 & $10,3 \pm 0,6$ & $10,1 \pm 0,5$ & $>0,05$ \\
\cline { 2 - 5 } & EG-2 & $10,3 \pm 0,6$ & $9,7 \pm 0,5$ & $<\mathbf{0 , 0 5}$ \\
\cline { 2 - 5 } $\begin{array}{c}\text { jump over the rope } \\
\text { (number of times) }\end{array}$ & KG & $28,4 \pm 2,1$ & $29,3 \pm 1,8$ & $>0,05$ \\
\cline { 2 - 5 } & EG-1 & $31,1 \pm 1,7$ & $36,2 \pm 2,1$ & $<\mathbf{0 , 0 5}$ \\
\hline
\end{tabular}

The analysis of table 1 showed that the results have changed in all indicators of children. In children from $\mathrm{KG}$, who were engaged in the standard method of performance coordination abilities became worse by 0.1 seconds at the same time, performance speed endurance abilities slightly improved from $28.4 \pm 2.1$ to $29.3 \pm 1.8$ ( $p>0.05$ ). Such results suggest that the standard method of teaching schoolchildren is not effective for the development of their physical qualities. Children in EG-1, who were engaged in the standard method and performed coordination exercises for 12-15 minutes after warm-up, improved their performance in both control exercises. In the test "shuttle run" performance improved from 10.3 \pm 0.6 to $10.1 \pm 0.5(\mathrm{p}>0.05)$, and in the test "jump over the rope" results improved from $31.1 \pm 1.7$ to $36.2 \pm 2.1$ $(p<0.05)$. Thus, we can state the fact that coordination training for schoolchildren is effective in terms of development of their physical qualities. Children in EG-2 have significantly improved their ability in both control exercises. In the test "shuttle run", performance improved from $10.3 \pm 0.6$ to $9.7 \pm 0.5(\mathrm{p}<0.05)$, and speed endurance improved by $9.2(p<0.05)$. Such data indicate the absolute effectiveness of the use of a differentiated approach based on typology, in working with younger schoolchildren.

\section{Discussion}

Coordination of movement is the ability of a person to accurately and quickly perform motor action. There is no doubt about the need to develop coordination abilities. Such abilities are necessary for life, activity, work, physical culture, sports, art and many other positions. The high level of development of coordination abilities allows the person not only to carry out movement precisely, but also to save the forces, the energy ${ }^{1-3,20}$. Studies have shown that coordination abilities are most effectively developed in primary school age and the results of this study confirm this ${ }^{4,5}$.

Some studies of the relationship between coordination abilities and physical qualities show that such a relationship exists ${ }^{6,7}$. Our study confirms these results with the following formulation-the higher the level of coordination, the higher the speed endurance of schoolchildren who are engaged in physical education at school and use coordination training for 12-15 minutes. Children who performed such exercises have improved their performance not only coordination abilities, but also speed endurance.

In physical education classes or sports clubs with older children, as a rule, an individual approach is used. At the same time, it is necessary to use a differentiated approach in classes with children of primary school age. An individual and differentiated approach allows to reveal the potential of physical and mental capabilities of the 
schoolchildren to reveal the reserves of his body and to show its advantages in comparison with other schoolchildren ${ }^{8,9}$. The criteria for a differentiated approach can be the height and weight of the schoolchildren, his physical or technical ability and many other criteria ${ }^{10,11,21}$.

One of the effective criteria of differentiation of schoolchildren into groups or subgroups is the typology, that is, the features of the manifestation of the properties of the nervous system ${ }^{12,13}$. If you determine the strength-weakness of the nervous system in the process of excitation in schoolchildren and give a commensurate load, the results are significantly improved. In working with schoolchildren who have a strong nervous system, you need to use an intense load, and in working with schoolchildren who have a weak nervous system - a volumetric load ${ }^{16,17}$. Under this, of course, children who prevail weak type of nervous system are not weak in principle. Such children go to the same goal, but in other ways. In work with such children it is more effective to use the repeated method, volume loading and visual methods. They are able to perform longer monotonous actions, have a high reactivity and the ability to master difficult coordination exercises $^{12,13,22}$. This means that with the help of volumetric load, schoolchildren with weak nervous system will be able effectively to increase their reactivity and master difficult coordination exercises

Thus, the new study for the first time established the influence of coordination training on the development of not only coordination abilities, but also speed endurance of children 7-8 years. The results of previous studies on the importance of coordination abilities, sensitive periods of their development, the use of a differentiated approach and some other positions are confirmed. The results of the study allow us to say that the aim of the study is achieved and the hypothesis is solved.

At school, physical education classes should be allocated from 12 to 15 minutes of time for coordination training. Such training increases the level of coordination abilities and promotes the development of physical qualities, such as speed endurance. A differentiated approach should be used in the work with younger schoolchildren. If you use a differentiated approach, which is based on the strength-weakness of the nervous system of children, their performance will improve significantly. Teachers, coaches, athletes can use the results of this study and apply the method of differentiated development of coordination and physical abilities, which is based on the strengthweakness of the nervous system of schoolchildren.
The study is relevant and promising for further study of different influences and abilities and qualities of children of different sex and age.

\section{Conclusions}

The study showed the effectiveness of the typological criterion in differentiating children into groups. If the physical education classes at school to develop coordination abilities of schoolchildren taking into account the strength of the nervous system, it will significantly improve the performance of coordination abilities and speed endurance.

\section{References}

1. Holodov ZHK, Khuznetsov VS. Theory and methodics of physical training and sports. Moscow: Akademia 2009. 480 p.

2. Issurin VB, Lyakh VI. Coordination abilities of athletes: basics of manifestation, evaluation and elucidation: a review. Journal of Athletic Enhancement 2017; 6(2).

https://doi.org/10.4172/23249080.1000255

3. Jaakkola J, Watt A, Kalaja S. Differences in the motor coordination abilities among adolescent gymnasts, swimmers and ice hockey players. Human Movement 2017; 1:44-50.

https://doi.org/10.1515/humo-2017-0006

4. Starosta W, Hirtz P. Sensitive and critical periods of motor co-ordination development and its relation to motor learning. Journal of Human Kinetics 2002; 7:19-28.

5. Feoktistov MF. Periods of sensitivity of development of physical abilities among various contingents of pupils at average school age. Uchenye zapiski universiteta imeni P.F. Lesgafta 2010; 62:118-20.

6. Bozdoğan TK, Kizilet A. The effect of coordination and plyometric exercises on agility, jumping and endurance ability in badminton players. International Journal of Sports Exercise \& Training Sciences 2017, 3(4):178-87. https://doi.org/10.18826/useeabd.345236

7. Jekauc D, Wagner MO, Herrmann C, Hegazy K, Woll A. Does physical selfconcept mediate the relationship between motor abilities and physical activity in 
adolescents and young adults? PLOS ONE 2017, 12(1):1-18.

https://doi.org/10.1371/journal.pone.01685

39

PMid: 28045914 PMCid: PMC5207408

8. Santos S, Coutinho D, Gonçalves B, Schöllhorn W, Sampaio J, Leite N. Differential learning as a key training approach to improve creative and tactical behaviour in Soccer. Research Quarterly for Exercise and Sport 2018, 89(1):11-24. https://doi.org/10.1080/02701367.2017.14 12063

PMid:29351500

9. Bakulev SE, Dveyrina OA, Savvina AS. Differentiated approach to the determination of major sports coordination abilities boxer. Uchenye zapiski universiteta imeni P.F. Lesgafta 2006; 20:3-9.

10. Shakhanova AV, Chelyshkova TV, Kuzmin AA, Silantyev MN, Grechishkina SS. Effect of team sports on aerobic performance of human body in view of somatotype. Indian Journal of Science and Technology 2016; 9(42): 104257.

11. Ion C, Serghei S, Constantin C. Differentiated physical training within the framework of a yearly training cycle of young footballers specialized on the position of goalkeeper. Journal of Physical Education and Sport 2018; 18(1):270-5.

12. Makarov YM, Hussain A-T. Typological profile of person properties of the basketball players aged 16-18 years old depending on the style of game activity. Uchenye zapiski universiteta imeni P.F. Lesgafta 2011; 73:122-4.

13. Drozdovski AK. The connection between typological complexes of properties of the nervous system, temperaments, and personality types in the professions and sports. Open Access Journal of Sports Medicine 2015; 6:72-161.

https://doi.org/10.2147/OAJSM.S75612
14. Shklyar BM. Usage of statistical methods in the pedagogical researches. Science Rise 2015; 5:39.

15. Lyakh, VI, Zdanevich AA. Work program on physical culture, grade 1-4. Moscow: Education 2010. 80 p.

16. Polevoy, G. The spatial orientation of the players with different type of nervous system. International Journal of Applied Exercise Physiology 2017; 6(4):1-6. https://doi.org/10.22631/ijaep.v6i1.112

17. Polevoy, G. The development of the ability to equilibrium football players 10 11 years with different Nervous System. Journal of Medical and Health Sciences 2018; 12(1):496-9.

18. Raigorodskiy DJ. Practical psychodiagnostics. Methodics and tests. Samara: Bakhrakh-M 2017. 672 p.

19. Clark-Carter D. Effect size and statistical power in psychological research. Irish Journal of Psychology 2007; 28:3-12. https://doi.org/10.1080/03033910.2007.10 446244

20. Vespalec T, Zhu W, Zvonar M. Relationship between physical activity and coordination: a middle-age adult study. Medicine \& Science in Sports \& Exercise 2014, 46:770.

https://doi.org/10.1249/01.mss.000049580 $8.88582 .1 \mathrm{f}$

21. Fiorilli G, Mitrotasios M, Iuliano E, Calcagno G, Di Cagno A. Agility and change of direction in soccer: Differences according to the player ages. Journal of Sports Medicine and Physical Fitness 2017, 57(12):1597-604.

PMid:27215771

22. Kostyunina LI, Kiryanova LA, Anisimova YA. Special features of the manifestation of nervous system typological properties among sprint track and field athletes. Uchenye zapiski universiteta imeni P.F. Lesgafta 2010; 62:38-42. 